\title{
Assessment of comorbidities in patients with deranged thyroid hormone levels
}

\author{
Sneha D. Narwade, Rohidas M. Barve*
}

Department of Pharmacology, B. J. Government Medical College, Pune, Maharashtra, India

\author{
Received: 29 May 2020 \\ Revised: 07 June 2020 \\ Accepted: 18 June 2020 \\ *Correspondence: \\ Dr. Rohidas M. Barve, \\ Email: rohidas.barve@yahoo.co.in
}

Copyright: $@$ the author(s), publisher and licensee Medip Academy. This is an open-access article distributed under the terms of the Creative Commons Attribution Non-Commercial License, which permits unrestricted non-commercial use, distribution, and reproduction in any medium, provided the original work is properly cited.

\begin{abstract}
Background: There is association of deranged thyroid hormone levels with various co-morbidities. Drugs for comorbidity may interact with each other and affect the outcome of treatment. So, this study was planned to find out comorbidities with deranged thyroid hormone levels and various possible drug interactions.

Methods: It was a prospective, observational study carried out at tertiary care hospital from November 2017 to June 2018. Thyroid hormonal levels reports were followed in OPD and online information system facility. Drugs interactions were checked by referring standard pharmacology textbooks, review articles and Medscape drug interaction checker. Approval from the Institutional Ethics Committee was taken before initiation of the study. Patients with deranged thyroid hormone levels were included in the study.

Results: Study was conducted in 111 patients of thyroid disorders. Spondylitis, asthma, acne cases were seen in hypothyroid patients whereas hypokalemic periodic paralysis, thyroid ophthalmopathy statistically significantly seen in hyperthyroid patients. Various concurrent medications such as calcium, carbamazepine decreases the effects of levothyroxine. For management of comorbidities various drugs are given which also interact among themselves significantly.

Conclusions: Diabetes mellites, obesity, spondylitis, lichen planus were more common in hypothyroidism while comorbidities like hypertension, hypokalemic periodic paralysis, thyroid ophthalmopathy were found to be more in hyperthyroidism. Incidence of drug interactions is found to be more with increased use of medications for comorbidities, so physicians should be careful while prescribing them. Due to drug interactions desired effects of drugs given for thyroid disorders may not be observed.
\end{abstract}

Keywords: Hypothyroidism, Hyperthyroidism, Diabetes mellitus, Comorbidity, Drug interactions

\section{INTRODUCTION}

Thyroid functions may be affected by various factors. Diagnosis of the thyroid dysfunction can be easily done if the clinical signs and symptoms are present. In elderly patients' clinical presentation is often atypical. In many cases laboratory findings are abnormal because of use of medications or presence of unrelated and non-thyroid medical illnesses. Many abnormalities in thyroid tests can be caused by various illnesses that do not directly involve the thyroid gland. Thyroid function tests revert to normal after recovery from the illness. Thyroid hormones act by binding to nuclear thyroid hormone receptors alpha and beta. Both receptors present in most of tissues. Thyroid receptor alpha is particularly abundant in brain, kidney, gonads, muscle and heart, whereas thyroid receptor beta expression is relatively high in the pituitary and liver. ${ }^{1}$ Thyroid hormones regulate cellular energy homeostasis. The overall prevalence of thyroid dysfunction is $12.5 \% .^{2}$ 
Thyroid hormones in excess decrease the insulin content of the pancreas. The co-existence of both diabetes and thyroid disorders has been associated with increased long-term morbidity and mortality. ${ }^{3}$

There is association between polycystic ovarian syndrome, liver injury and thyroid dysfunction. Thus, increase or decrease in thyroid hormonal level affects various organs of our body.

Drug interactions which may interfere with the therapeutic outcome or be responsible for adverse effects. The severity of drug interactions in most cases is highly unpredictable. However, the doctor must know which are drugs not to be prescribed concurrently

There are various factors adversely affecting levothyroxine performance which include comorbid conditions and their treatments, diet, tolerability of medication, and compliance with instructions for administration

Many factors contribute directly or indirectly to the failure of levothyroxine therapy. These can adversely affect treatment satisfaction and can lead to unnecessary consumption of healthcare resources in the form of increased physician and pharmacy visits, laboratory costs, and medication adjustments. ${ }^{4}$ Absorption of thyroxine must be efficient and consistent in order for a patient to experience the sustained benefits of treatment.

Many factors such as patient compliance, physiological disturbances, drug-drug interactions and mal-absorptive disease states can increase a patient's dosage requirements for thyroxine. ${ }^{5}$ So this study was planned to find out comorbidities with deranged thyroid hormone levels and various possible drug interactions.

\section{METHODS}

It was a cross-sectional, prospective, observational study is conducted for a period of 3 month out door patient unit in medicine department for a period of 8 month in medicine department at Sassoon general hospital, Pune from November 2017 to June 2018. This study was commenced after getting approval from the Institutional Ethics Committee. Study was conducted among patients with deranged thyroid hormone levels.

\section{Inclusion criteria}

Inclusion criteria were patients with deranged thyroid hormone levels.

\section{Exclusion criteria}

Exclusion criteria were critically ill patients, unconscious patients and patients who were not willing to participate in the study.
Deranged thyroid hormonal levels reports were followed in outdoor patient unit (OPD), wards and online information system facility for presence of other illnesses and medications. Detailed history was taken from patients and entered in case record form. Cases were followed up by phone calls and in OPD on their visits. Data regarding thyroid function tests and complaints of patients were collected. Drug interactions were checked by referring standard pharmacology textbook, review articles and Medscape drug interaction checker. Medscape drug interaction checker, shows all possible drug interactions with prescribed drugs.

Prescriptions were verified for any alteration in dosage of drugs. The collected data was checked, reviewed and organized for its completeness. This data was entered in excel sheet and analyzed. Fisher exact test was used for statistical analysis.

\section{RESULTS}

Total number of patients included in this study were 111 . Out of these, 91 patients were of hypothyroidism and 20 were of hyperthyroidism. Study population consisted of $85 \%$ females and $15 \%$ males. The results indicate that $19 \%$ hypothyroid cases were obese and $7 \%$ were morbid obese while $10 \%$ of hyperthyroid cases were obese. TSH levels were significantly higher in hypothyroid patients as compared to hyperthyroid. T3 and T4 levels were found to be significantly higher in hyperthyroid patients as compared to hypothyroid (Table 1).

The most common comorbidities in hypothyroidism included diabetes mellitus $41 \%$, hypertension $31 \%$ and obesity $26 \%$ whereas hypertension $45 \%$, diabetes mellitus $20 \%$ and dyslipidemia $15 \%$ were common in hyperthyroidism. Hypokalemic periodic paralysis was found to be associated with hyperthyroidism ( $\mathrm{p}$ value 0.03) (Figure 1). Body ache, edema and irregular menses were common in hypothyroidism. Increase in appetite was significantly common in hyperthyroid patients $(p$ value is 0.02 ). Surprisingly $15 \%$ of hyperthyroid patients were having edema (Table 2).

Due to various comorbidities in study population multiple medications were prescribed for patients. This raised the chances of drug interactions as indicated by Medscape drug interactions checker. These interactions may be responsible for various non-specific effects observed in study population as shown in (Table 3 ).

Drug interactions between levothyroxine and other concurrent medications such as calcium, ferrous sulphate, carbamazepine was possible as per Medscape drug interaction checker. Possible drug interactions between acetyl salicylic acid and enalapril, propranolol and calcium, folic acid and methotrexate, diclofenac and enalapril were observed in this study population (Table 3). 


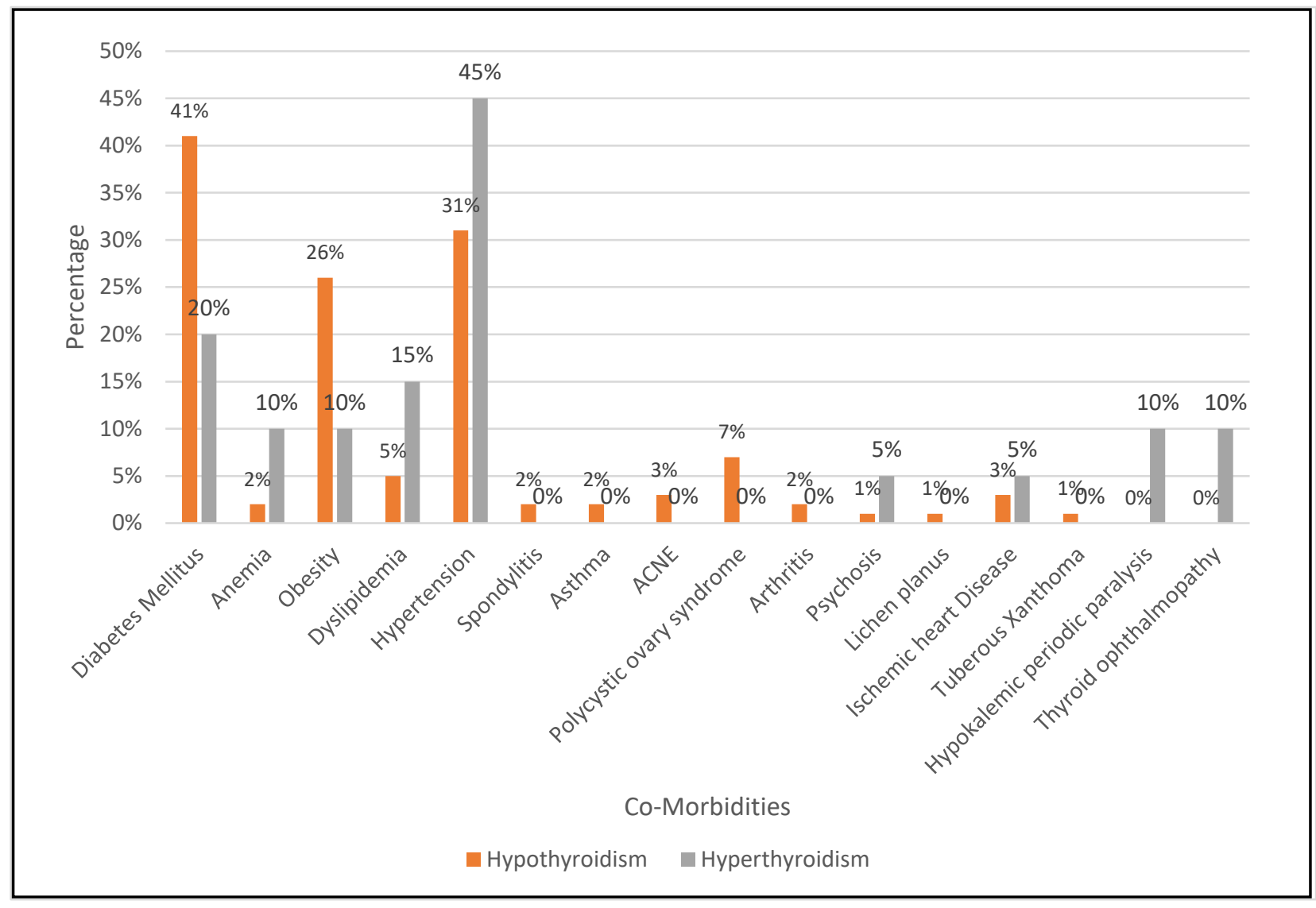

Figure 1: Distribution of comorbidities in study population.

Table 1: Demographic details of study population.

\begin{tabular}{|c|c|c|c|}
\hline Characteristics & $\begin{array}{l}\text { Hypothyroidism n=91 (82\%) } \\
\text { N (\%) }\end{array}$ & $\begin{array}{l}\text { Hyperthyroidism } n=20(18 \%) \\
N(\%)\end{array}$ & $P$ value \\
\hline Age in years & $42(30-54)$ & $39(30-48)$ & 0.63 \\
\hline \multicolumn{4}{|l|}{ Sex } \\
\hline Male & $14(15)$ & $3(15)$ & \multirow{2}{*}{$>0.95$} \\
\hline Female & $77(85)$ & $17(85)$ & \\
\hline \multicolumn{4}{|l|}{ BMI } \\
\hline Underweight & $2(2)$ & $1(5)$ & \multirow{5}{*}{0.39} \\
\hline Normal & $36(41)$ & $11(60)$ & \\
\hline Overweight & $28(31)$ & $4(25)$ & \\
\hline Obesity & $17(19)$ & $2(10)$ & \\
\hline Morbid obesity & $6(7)$ & - & \\
\hline \multicolumn{4}{|l|}{ TSH } \\
\hline$<0.5$ & $8(9)$ & $13(72)$ & \multirow{3}{*}{$<0.001 *$} \\
\hline $0.5-5$ (normal) & $25(28)$ & $4(22)$ & \\
\hline$>5$ & $55(63)$ & $1(6)$ & \\
\hline \multicolumn{4}{|l|}{ T3 } \\
\hline$<0.8$ & $6(7)$ & - & \multirow{3}{*}{$<0.001 *$} \\
\hline $0.8-2$ & $78(89)$ & $7(39)$ & \\
\hline$>2$ & $4(5)$ & $11(62)$ & \\
\hline \multicolumn{4}{|l|}{$\mathbf{T 4}$} \\
\hline$<5$ & $12(14)$ & - & \multirow{3}{*}{$<0.001 *$} \\
\hline $5-13$ & $71(81)$ & $9(50)$ & \\
\hline$>13$ & $5(6)$ & $9(50)$ & \\
\hline
\end{tabular}


Table 2: Effects of deranged thyroid hormone levels on body.

\begin{tabular}{|llll|}
\hline Effects & Hypothyroidism n=91 (82\%) & Hyperthyroidism n=20 (18\%) & P value \\
\hline Increased appetite & $\mathbf{N}(\mathbf{\%})$ & $\mathbf{N}(\mathbf{\%})$ & $0.02^{*}$ \\
\hline Decrease appetite & $1(1)$ & $3(15)$ & $>0.95$ \\
\hline Joint pain & $7(8)$ & $1(5)$ & $>0.95$ \\
\hline Body ache & $3(3)$ & - & $>0.95$ \\
\hline Constipation & $12(13)$ & $2(10)$ & $>0.95$ \\
\hline Edema & $8(9)$ & $1(5)$ & 0.76 \\
\hline Dry skin & $18(20)$ & $3(15)$ & 0.58 \\
\hline Muscle weakness & $5(5)$ & - & 0.35 \\
\hline Sleepiness & $8(9)$ & - & 0.14 \\
\hline Hair fall & $10(11)$ & $1(5)$ & 0.35 \\
\hline Palpitations & $7(8)$ & - & 0.30 \\
\hline Increased sensitivity to cold & $4(4)$ & $2(10)$ & 0.45 \\
\hline Infertility & $3(3)$ & - & $>0.95$ \\
\hline No effects & $1(1)$ & - & 0.36 \\
\hline Fatigue & $15(16)$ & $5(25)$ & $>0.95$ \\
\hline Forgetfulness & $8(9)$ & $2(10)$ & 0.58 \\
\hline Breathlessness & $5(5)$ & - & $>0.95$ \\
\hline stiffness & $7(8)$ & $1(5)$ & $>0.95$ \\
\hline Tingling sensation in hands & $1(1)$ & - & $>0.95$ \\
\hline Electrolyte imbalance & $1(1)$ & - & $>0.95$ \\
\hline Irregular menses & $1(1)$ & - & 0.12 \\
\hline
\end{tabular}

Table 3: Various possible drug interactions as per Medscape drug interactions checker.

\begin{tabular}{|c|c|c|c|}
\hline $\begin{array}{l}\text { Medications for } \\
\text { thyroid disorders }\end{array}$ & $\begin{array}{l}\text { Concurrent } \\
\text { medications }\end{array}$ & Drug interactions & Effect \\
\hline Levothyroxine & Calcium & $\begin{array}{l}\text { Calcium decreases absorption of } \\
\text { levothyroxine }\end{array}$ & $\begin{array}{l}\text { Sleepiness, constipation and dry } \\
\text { skin }\end{array}$ \\
\hline Levothyroxine & Ferrous sulphate & $\begin{array}{l}\text { Ferrous sulphate decreases } \\
\text { absorption of levothyroxine }\end{array}$ & $\begin{array}{l}\text { Decrease appetite, sleepiness, } \\
\text { body ache, swelling over body }\end{array}$ \\
\hline Levothyroxine & $\begin{array}{l}\text { Acetyl salicylic acid } \\
\text { enalapril }\end{array}$ & $\begin{array}{l}\text { Acetyl salicylic acid decreases } \\
\text { antihypertensive effect of enalapril }\end{array}$ & $\begin{array}{l}\text { Weight gain due to significant } \\
\text { decrease in renal function }\end{array}$ \\
\hline Propranolol & Calcium & $\begin{array}{l}\text { Calcium decreases the effect of } \\
\text { propranolol }\end{array}$ & $\begin{array}{l}\text { Tremors still persist, despite of } \\
\text { propranolol given }\end{array}$ \\
\hline Levothyroxine & $\begin{array}{l}\text { Atenolol } \\
\text { acetyl salicylic acid }\end{array}$ & $\begin{array}{l}\text { Atenolol and acetyl salicylic acid } \\
\text { increases serum potassium level }\end{array}$ & Chest pain \\
\hline Levothyroxine & Carbamazepine & $\begin{array}{l}\text { Carbamazepine decreases the } \\
\text { levels of levothyroxine by } \\
\text { increasing metabolism }\end{array}$ & $\begin{array}{l}\text { Swelling over body and } \\
\text { decrease interest in work }\end{array}$ \\
\hline Levothyroxine & $\begin{array}{l}\text { Folic acid } \\
\text { methotrexate }\end{array}$ & $\begin{array}{l}5 \mathrm{mg} \text { of folic acid daily decrease } \\
\text { the efficacy methotrexate }\end{array}$ & $\begin{array}{l}\text { knee pain complaints continue } \\
\text { despite of taking medication }\end{array}$ \\
\hline Levothyroxine & $\begin{array}{l}\text { Diclofenac } \\
\text { Enalapril }\end{array}$ & $\begin{array}{l}\text { The combination of diclofenac and } \\
\text { enalapril can produce marked } \\
\text { hyperkalemia }\end{array}$ & Chest pain \\
\hline Levothyroxine & Omeprazole & $\begin{array}{l}\text { Omeprazole decreases the efficacy } \\
\text { of levothyroxine }\end{array}$ & Edema, fatigue and dry hairs \\
\hline
\end{tabular}

\section{DISCUSSION}

The study showed various comorbidities associated with thyroid disorders. Patients were on treatment for both thyroid disorders as well as for comorbidities. Despite of taking multiple medications, complete symptomatic relief was not there which may be due to possible drug interactions. In present study, hypothyroidism is more common in female population in concordance with Anandhasayanam et al study. ${ }^{6}$ Paul et al observed that 
$34.1 \%$ of hypothyroid patients were suffering from asthma, which is quite high as compared to our study. ${ }^{7}$

Percentage of obesity and hypertension in hypothyroid patients was consistently with Paul et al whereas diabetic cases were more in our study.

In Pola et al study, prevalence of thyroid disorder was $15.35 \%$ in lichen planus patients. ${ }^{8}$ Lichen planus patients were associated with thyroid disease, specifically with hypothyroidism. In our study, there was association of $1 \%$ lichen planus cases with hypothyroidism. The possible mechanism behind this association is still unresolved and merits further investigation.

Studies by Lam et al showed the common association of hypokalaemic periodic paralysis and hyperthyroidism supporting our findings. ${ }^{9}$ Irving et al and Zamfirescu et al study showed that simultaneous administration of thyroxine and ferrous sulphate causes a recurrence of the hypothyroid state in some patients..$^{5,10}$

In our study, probable drug interaction between calcium salts and levothyroxine led to decreased absorption of levothyroxine and hence complaints of sleepiness, constipation, dry skin. Similarly, ferrous sulphate may have decreased absorption of levothyroxine, leading to complaints of decreased appetite, sleepiness, body ache, swelling over body in some patients. McMillan et al study, $47.5 \%$ of patients taking calcium supplements and $11.9 \%$ of patients taking iron supplements caused malabsorption of levothyroxine. ${ }^{4}$

One case report confirmed the importance of timing for patients for patients taking calcium and levothyroxine. ${ }^{11}$ They have shown that taking calcium within four hours of levothyroxine might decrease absorption of levothyroxine by nearly a third. Patients who have taken levothyroxine with calcium consistently for years might have had doses adjusted so plasma levels remained at therapeutic levels.

In our study, patients who were on calcium and ferrous sulfate, carbamazepine, phenytoin needed increase in levothyroxine dose requirement similar to Qari et al study. ${ }^{12}$

In our study patients who were on daily methotrexate and folic acid treatment for rheumatoid arthritis did not show good response to treatment similar findings are reported in other study by Khanna et al. ${ }^{13}$ The national rheumatoid arthritis society in the UK, recommended 5-10 $\mathrm{mg}$ of folic acid weekly to reduce side effects of methotrexate. Taking higher doses may reduce the efficacy of methotrexate, so most rheumatologists recommend administration of folic acid one or two days after the methotrexate, and in particular not taking it on the same day as the methotrexate.
As per Horacek et al study, thyroid function monitoring early in the course of carbamazepine treatment seems advisable. ${ }^{14}$ Because In patients with no thyroid disorder, carbamazepine caused subtle hormonal changes of no clinical relevance, due to adaptive response. In hypothyroid patients with replacement therapy this adaptation is lacking, and carbamazepine may precipitate subclinical or overt hypothyroidism.

In our study, patients who were on levothyroxine and pantoprazole showed decreased response to levothyroxine similar to Sachmechi et al study. ${ }^{15}$ Proton pump inhibitors modify the absorption of levothyroxine by reduction of gastric acid secretion or by increasing metabolic clearance of levothyroxine.

\section{CONCLUSION}

Diabetes mellites, obesity, spondylitis, asthma, lichen planus was more common in hypothyroidism while comorbidities like hypertension, hypokalemic periodic paralysis, thyroid ophthalmopathy were found to be more in hyperthyroidism. Incidence of drug interactions is found to be more with increased use of medications for comorbidities. To achieve adequate response to the treatment, physicians should be careful while choosing concurrent medications for comorbidity. Further studies need to be carried out to verify our findings.

\section{Funding: No funding sources \\ Conflict of interest: None declared}

Ethical approval: The study was approved by the Institutional Ethics Committee

\section{REFERENCES}

1. Fauci AS, Braunwald E, Kasper DL, Hauser SL, Longo DL, Jameson JL, et al. Harrison's Principles of Internal Medicine,19th ed. New York: McGraw Hill; 2015.

2. Velayutham K, Selvan S, Unnikrishnan AG. Prevalence of thyroid dysfunction among young females in a South Indian population. Indian Journal of Endocrinology and Metabolism. 2015;19(6):781-4.

3. Chandel K, Singh RB, Kumar S, Gupta A, Nath K. Evaluation of Thyroid Hormone dysfunction in patients of Type-2 Diabetes mellitus. Indian J Clin Anatomy Physiology. 2016;3(1):21-3.

4. McMillan M, Rotenberg KS, Vora K, Sterman A. Comorbidities, Concomitant Medications, and Diet as Factors Affecting Levothyroxine Therapy: Results of the CONTROL Surveillance. Project. 2016:16:53-68.

5. Irving SA, Vadiveloo $\mathrm{T}$, Leese GP. Drugs that interact with levothyroxine: an observational study from the Thyroid Epidemiology, Audit and Research Study. Clin Endocrinology. 2015;82:136-41.

6. Anandhasayam A, Arivudainambi T, Kanan S. Prevalence of hypothyroidism and its co-morbidities in relation to the causes and risk factors in patients 
undergoing levothyroxine therapy. Int J Pharmaceutical Sci Res. 2016;7(3):1251-7.

7. Paul J, Dasgupta S. Co-morbidities in Hypothyroid Patients in a Tertiary Health Care Hospital in India. $\mathrm{J}$ Thyroid Disorders Ther. 2012;1(2):1-4.

8. Pola GMJ, Pendas SLS, Romero SJM. Thyroid Disease and Oral Lichen Planus as Comorbidity: A Prospective Case-Control Study. Dermatology. 2016;232:214-9.

9. Lam L, Nair R, Tingle L. Thyrotoxic periodic paralysis. Thyrotoxic periodic paralysis. Proc (Bayl Univ Med Cent). 2006;19:126-9.

10. Zamfirescu I, Carlson HE. Absorption of Levothyroxine When Co-administered with Various Calcium Formulations. Thyroid. 2011;21(5):483-6.

11. Mazokopakis E, Giannakopoulos G, Starakis L. Interaction between levothyroxine and calcium carbonate. Canadian Family Physician. 2008;54:39.
12. Qari F. Hypothyroidism in Clinical Practice. J Family Med Primary Care. 2014;3(2):98-101.

13. Khanna D, Park G, Paulus H, Simpson K. Reduction of the Efficacy of Methotrexate by the Use of Folic Acid. Arthritis Rheumatism. 2005;52(10):3030-8.

14. Horacek J, Simko J, Waberzinek G. Carbamazepine and risk of hypothyroidism: a prospective study. Endocrine Abstracts. 2007:318.

15. Sachmechi I, Reich D, Aninyei M, Wibowo F. Effect of Proton Pump Inhibitors on Serum Thyroidstimulating hormone level in euthyroid patients treated with levothyroxine for hypothyroidism. Endocrine Practice. 2007;13(4):345-9.

Cite this article as: Narwade SD, Barve RM. Assessment of comorbidities in patients with deranged thyroid hormone levels. Int J Basic Clin Pharmacol 2020;9:1044-9. 